\title{
LIAPUNOV-TYPE INEQUALITIES AND NEUMANN BOUNDARY VALUE PROBLEMS AT RESONANCE
}

\author{
A. Cañada, J. A. Montero And S. Villegas
}

\begin{abstract}
This paper is devoted to the study of resonant nonlinear boundary value problems with Neumann boundary condition. First we consider the linear situation doing a careful analysis on the existence of nontrivial solutions. This analysis involves Liapunov-type inequalities with the $L_{p}-$ norm of the coefficient function for $1 \leqslant p \leqslant \infty$. We carry out a complete treatment of the problem for any constant $p \geqslant 1$. Then, this is combined with Schauder fixed point theorem to obtain new results about the existence and uniqueness of solutions for resonant nonlinear problems.
\end{abstract}

Mathematics subject classification (2000): 34B15, 34B05.

Key words and phrases: Neumann boundary value problems, resonance, Liapunov inequalities, existence and uniqueness.

\section{REFERENCES}

[1] R. C. Brown, D. B. Hinton, Lyapunov inequalities and their applications, Survey on Classical Inequalities, T. M. Rassias, ed. Kluwer, Dordrecht, 2000, 1-25.

[2] G. CRoce, B. DACorogna, On a generalized Wirtinger inequality, Discrete and Continuous Dynamical Systems, 9, (2003), 1329-1341.

[3] B. Dacarogna, W. Gangbo and N. Subía, Sur une généralisation de l'inégalité de Wirtinger, Ann. Inst. Henri Poincaré, Anal. Non Linéaire, 9, (1992), 29-50.

[4] P. DRÁBEK, Nonlinear eigenvalue problems and Fredholm altrnative, In Nonlinear Differential Equations, P. Drábek, P. Krejči and P. Takáć, Editors. Research Notes in Mathematics Series, 404, Chapman and Hall/CRC, London, 1999, 1-46.

[5] P. Hartman, Ordinary Differential Equations, John Wiley and Sons Inc., New York-London-Sydney, 1964.

[6] W. Huaizhong, L. Yong, Neumann boundary value problems for second-order ordinary differential equations across resonance, SIAM J. Control and Optimization, 33, (1995), 1312-1325.

[7] L. Kotin, A generalization of Liapunov's inequality, J. Math. Anal. Appl., 102, (1984), 585-598.

[8] J. MAWHIN, J. R. WARD AND M. WILLEM, Variational methods and semilinear elliptic equations, Arch. Rational Mech. Anal., 95, (1986), 269-277. 